\title{
Mechanisms of resistance to $\beta$-lactam antibiotics amongst Pseudomonas aeruginosa isolates collected in the UK in 1993
}

\author{
H. Y. CHEN, MEI YUAN and D. M. LIVERMORE \\ Department of Medical Microbiology, The London Hospital Medical College, Turner Street, London E1 2AD
}

\begin{abstract}
Summary. Antimicrobial resistance among 1991 Pseudomonas aeruginosa isolates collected at 24 UK hospitals during late 1993 was surveyed. Three-hundred and seventy-two of the isolates were resistant, or had reduced susceptibility, to some or all of azlocillin, carbenicillin, ceftazidime, imipenem and meropenem, and the mechanisms underlying their behaviour were examined. Only 13 isolates produced secondary $\beta$-lactamases: six possessed PSE-1 or PSE-4 enzymes and seven had novel OXA enzyme types. Those with PSE types were highly resistant to azlocillin and carbenicillin whereas those with OXA enzymes were less resistant to these penicillins. Chromosomal $\beta$-lactamase derepression was demonstrated in 54 isolates, most of which were resistant to ceftazidime and azlocillin although susceptible to carbenicillin and carbapenems. $\beta$-Lactamase-independent "intrinsic" resistance occurred in 277 isolates and is believed to reflect some combination of impermeability and efflux. Two forms were seen: the classical type, present in 195 isolates, gave carbenicillin resistance (MIC $>128 \mathrm{mg} / \mathrm{L}$ ) and reduced susceptibility to ciprofloxacin and to all $\beta$-lactam agents except imipenem; a novel variant, seen in 82 isolates, affected only azlocillin, ceftazidime and, to a small extent, meropenem. Resistance to imipenem was largely dissociated from that to other $\beta$-lactam agents, and probably reflected loss of $\mathrm{D} 2$ porin, whereas resistance to meropenem was mostly associated with intrinsic resistance to penicillins and cephalosporins. Comparison of the present results with those of a similar study in 1982 revealed significant increases in the proportions of isolates with intrinsic resistance or stable derepression $\left(p<0.01, \chi^{2}\right.$ test $)$. Isolates with secondary $\beta$-lactamases appeared significantly rarer than in $1982\left(\mathrm{p}<0.01, \chi^{2}\right.$ test), but this comparison was distorted by outbreak strains.
\end{abstract}

\section{Introduction}

Most Pseudomonas aeruginosa isolates are susceptible to ureido- and carboxy-penicillins, ceftazidime, cefoperazone, cefsulodin, aztreonam, imipenem and meropenem. Nevertheless, resistance to these agents can arise by various mechanisms, including mutational derepression of the AmpC chromosomal $\beta$ lactamase, ${ }^{1,2}$ acquisition of secondary plasmid- or transposon-mediated $\beta$-lactamases, ${ }^{3,4}$ reduced permeability $^{5,6}$ or multi-drug efflux ${ }^{7,8}$ (see Discussion) or, finally, in the case of imipenem, via loss of the D2 porin..$^{9,10}$

During 1993 the incidence of antibiotic resistance amongst $P$. aeruginosa isolates in the UK was surveyed. ${ }^{11}$ Microbiology laboratories in each of 24 hospitals (see Acknowledgements) collected up to 100 consecutive non-replicate isolates between 1 Sept. and 31 Dec., 1993, and sent them to this laboratory. Of 2184 isolates received, 1991 were confirmed as viable $P$. aeruginosa. Resistance rates were $10.4 \%$ to azlocillin $16 \mathrm{mg} / \mathrm{L}, 11.7 \%$ to carbenicillin $128 \mathrm{mg} / \mathrm{L}$, $9.6 \%$ to ceftazidime $4 \mathrm{mg} / \mathrm{L}, 2.5 \%$ to imipenem $4 \mathrm{mg} / \mathrm{L}$ and $1.1 \%$ to meropenem $4 \mathrm{mg} / \mathrm{L}$. For carbenicillin and ceftazidime, these frequencies were increased significantly $(p<0.05)$ compared to those found in a similar study in $1982 .{ }^{12}$ Although resistance to azlocillin, $16 \mathrm{mg} / \mathrm{L}$ was not increased significantly $(p>0.05)$ there was a significant rise $(p<0.01)$ in the proportion of isolates resistant to the drug at $32 \mathrm{mg} / \mathrm{L} .{ }^{12}$ Imipenem and meropenem were not tested in 1982. In the present study the mechanisms underlying these resistances were investigated and their current incidences were compared to those found in 1982. 


\section{Materials and methods}

\section{Selection of isolates}

Of the $1991 P$. aeruginosa isolates collected in the 1993 survey, ${ }^{11} 372$ were examined, being selected because they were resistant to one or more of the following drug concentrations: azlocillin $16 \mathrm{mg} / \mathrm{L}$; carbenicillin $128 \mathrm{mg} / \mathrm{L}$; ceftazidime $4 \mathrm{mg} / \mathrm{L}$; imipenem $4 \mathrm{mg} / \mathrm{L}$, meropenem $4 \mathrm{mg} / \mathrm{L}$. These concentrations were selected to facilitate discrimination of normal isolates from those with abnormally reduced susceptibility, and do not invariably coincide with clinical breakpoints. ${ }^{11}$ The MIC tests allowing this categorisation were performed on IsoSensitest Agar (Chipath) with inocula of $10^{4} \mathrm{cfu} / \mathrm{spot}$, and have been described already. ${ }^{11}$ Reference $P$. aeruginosa strains included NCTC10662, as the control in the susceptibility testing, R20, as a control with known inducibility of AmpC $\beta$-lactamase, ${ }^{13}$ and 1405-con and 2297-con, with derepressed AmpC $\beta$-lactamase expression. ${ }^{13}$ Transconjugants of $P$. aeruginosa PU21 and Escherichia coli $\mathrm{K}-12 \mathrm{~J} 53$ and $\mathrm{J} 62^{2,14}$ served as sources of reference plasmid- and transposonmediated enzymes.

\section{Antimicrobial agents}

Antimicrobial agents were from suppliers as follows: azlocillin sodium and ciprofloxacin, Bayer, Newbury, Berkshire; ampicillin sodium, carbenicillin disodium, clavulanate lithium and cloxacillin sodium, SmithKline Beecham, Brockham Park, Surrey; cephaloridine and oxacillin, Sigma; cefoxitin and imipenem, Merck, Hoddesdon, Hertfordshire; ceftazidime, Glaxo, Greenford, Middlesex; meropenem, Zeneca, Macclesfield, Cheshire; and nitrocefin, BBL, Cockeysville, MD, USA.

\section{$\beta$-Lactamase detection and typing}

Cultures were grown overnight on nutrient agar plates at $37^{\circ} \mathrm{C}$, then harvested by washing into $1.5-\mathrm{ml}$ volumes of $0.1 \mathrm{M}$ phosphate buffer, $\mathrm{pH} \mathrm{7.0.} \mathrm{The}$ washings were transferred to Eppendorf tubes and sonicated for $2 \times 30 \mathrm{~s}$ at an amplitude of $12 \mu \mathrm{m}$, with intermediate cooling on ice. Three $25-\mu 1$ samples of each sonicate were transferred to wells in a microtitration plate. One well was supplemented with $25 \mu \mathrm{l}$ of $0.3 \mathrm{~mm}$ cloxacillin in $0.1 \mathrm{M}$ phosphate buffer, pH 7.0 , one with $25 \mu 1$ of $0.3 \mathrm{~mm}$ clavulanate in $0.1 \mathrm{M}$ phosphate buffer, $\mathrm{pH} 7.0$ and the third with drug-free buffer. After $10 \mathrm{~min}$ at room temperature, $25-\mu \mathrm{l}$ of $0.3 \mathrm{~mm}$ nitrocefin in $0.1 \mathrm{M}$ phosphate buffer, $\mathrm{pH} 7.0$, were added to each well. The appearance of a red colour, indicating $\beta$-lactamase activity, was noted in comparison to the controls (R20,1405-con and 2297-con).

\section{Iso-electric focusing of $\beta$-lactamases}

$\beta$-Lactamase extracts were prepared as for the enzyme detection tests described above, except that $0.01 \mathrm{M}$, rather than $0.1 \mathrm{M}$, phosphate buffer was used. After centrifugation for $2 \mathrm{~min}$ at $12000 \mathrm{~g}$, the supernates were subjected to electrofocusing at $15 \mathrm{~W}$ constant power in polyacrylamide gels $(220 \times 100 \times 1 \mathrm{~mm})$ containing ampholines (Pharmacia, Milton Keynes, Buckinghamshire) $2 \% \mathrm{v} / \mathrm{v}$ of various $\mathrm{pH}$ ranges. ${ }^{15}$ Enzyme activities were detected by overlaying the gel with $0.5 \mathrm{~mm}$ nitrocefin in $0.1 \mathrm{M}$ phosphate buffer, $\mathrm{pH} 7 \cdot 0$, and observing for the appearance of pink bands. Identification of $\beta$-lactamases was by comparison to reference enzymes, run in tracks adjacent to the test samples.

\section{Assays of $\beta$-lactamase activity}

Cultures were grown overnight at $37^{\circ} \mathrm{C}$ in $25-\mathrm{ml}$ volumes of nutrient broth with orbital shaking at $150 \mathrm{rpm}$, then diluted into warm $\left(37^{\circ} \mathrm{C}\right) 250-\mathrm{ml}$ volumes of the same broth. Incubation was continued for $4 \mathrm{~h}$ under the previous conditions. Subsequently, the cells were harvested by centrifugation at $5000 \mathrm{~g}$, washed once in $0.1 \mathrm{M}$ phosphate buffer, $\mathrm{pH} 7 \cdot 0$, resuspended in $8 \mathrm{ml}$ of the same buffer and subjected to two alternate cycles of freezing and thawing. Debris and residual cells were removed by ultracentrifugation for $30 \mathrm{~min}$ at $100000 \mathrm{~g}$ and $4^{\circ} \mathrm{C}$. The supernates were assayed against $0.5 \mathrm{~mm} \beta$-lactam solutions in $0.1 \mathrm{M}$ phosphate buffer, $\mathrm{pH} 7 \cdot 0$, by UV spectrophotometry at $37^{\circ} \mathrm{C}$. Substrates and wavelengths were: ampicillin, benzylpenicillin and carbenicillin, $235 \mathrm{~nm}$; oxacillin, $265 \mathrm{~nm}$; and cephaloridine, $295 \mathrm{~nm}$.

\section{$\beta$-Lactamase induction assays}

Sonicates were prepared from logarithmic phase cells in nutrient broth cultures that had or had not been exposed to cefoxitin $500 \mathrm{mg} / \mathrm{L}$ for $4 \mathrm{~h}$ and were assayed against $0 \cdot 1 \mathrm{~mm}$ nitrocefin in $0.1 \mathrm{~mm}$ phosphate buffer, $\mathrm{pH} 7 \cdot 0 .{ }^{13}$ Activity was standardised against protein concentration, assayed by the method of Lowry et al. ${ }^{16}$

\section{Data handling and analysis}

Data analysis was with the programs Statview $\mathrm{SE}+$ Graphics and STATXACT. Comparisons of susceptibility data for different groups of isolates were by $\chi^{2}$ or Fisher's exact tests, as appropriate to the sample numbers.

\section{Results}

\section{Categorisation of isolates resistant to penicillins or ceftazidime}

Nitrocefin tests in the presence and absence of $0.1 \mathrm{~mm}$ cloxacillin or clavulanate were performed on 344 isolates selected as resistant to one or more of azlocillin $16 \mathrm{mg} / \mathrm{L}$, carbenicillin $128 \mathrm{mg} / \mathrm{L}$ or ceftazidime $4 \mathrm{mg} / \mathrm{L}$. Most (274), like the $\beta$-lactamaseinducible control strain R20, gave a pink colour in the 
Table I. Properties of isolates with secondary $\beta$-lactamases and of their enzymes

\begin{tabular}{|c|c|c|c|c|c|c|c|c|c|c|c|c|}
\hline \multirow[t]{2}{*}{ Isolate no. } & \multicolumn{5}{|c|}{$\mathrm{MIC}(\mathrm{mg} / \mathrm{L})$} & \multicolumn{2}{|c|}{$\beta$-Lactamase } & \multicolumn{5}{|c|}{$\begin{array}{l}\text { Relative hydrolysis rates } v s 0.5 \mathrm{mM} \\
\text { antibiotic }\end{array}$} \\
\hline & $\mathrm{Cb}$ & $\mathrm{Az}$ & $\mathrm{Caz}$ & $\operatorname{Imp}$ & Mem & $\mathrm{pI}$ & Alignment & PenG & Amp & $\mathrm{Cb}$ & Oxa & Cld \\
\hline 85 & 4096 & 512 & 4 & 4 & 2 & $5 \cdot 7$ & $=$ PSE-1 & 100 & 115 & 86 & 10 & 9 \\
\hline 723 & 4096 & 512 & 4 & 1 & $0 \cdot 125$ & $5 \cdot 7$ & $=$ PSE-1 & 100 & 106 & 93 & 10 & 10 \\
\hline 1294 & 4096 & 512 & 4 & 4 & 1 & $5 \cdot 7$ & $=$ PSE-1 & 100 & 127 & 118 & 11 & 11 \\
\hline 1856 & 4096 & 256 & 2 & 4 & 1 & $5 \cdot 3$ & $=$ PSE-4 & 100 & 106 & 105 & 10 & 12 \\
\hline 2223 & 4096 & 512 & 4 & 4 & 1 & $5 \cdot 7$ & $=$ PSE-1 & 100 & 101 & 84 & 8 & 8 \\
\hline 2312 & 4096 & 512 & 8 & 4 & 2 & 5.7 & $=$ PSE-1 & 100 & 100 & 101 & 9 & 16 \\
\hline PSE-1* & $\ldots$ & $\ldots$ & $\ldots$ & $\ldots$ & $\ldots$ & $5 \cdot 7$ & $\ldots$ & 100 & 107 & 99 & 10 & 10 \\
\hline PSE-4* & & & $\ldots$ & $\ldots$ & $\ldots$ & $5 \cdot 3$ & $\ldots$ & 100 & 127 & 89 & 9 & 11 \\
\hline 520 & 512 & 128 & 4 & 1 & 0.5 & $7 \cdot 5$ & $=\mathrm{OXA}-4$ & 100 & 874 & 79 & 537 & 67 \\
\hline 543 & 256 & 64 & 2 & 2 & 0.25 & $7 \cdot 5$ & $=\mathrm{OXA}-4$ & 100 & 914 & 101 & 453 & 115 \\
\hline 556 & 512 & 128 & 4 & 1 & 0.5 & $7 \cdot 5$ & $=$ OXA -4 & 100 & 1293 & 52 & 549 & 72 \\
\hline OXA-4* & $\ldots$ & $\ldots$ & $\ldots$ & $\ldots$ & $\ldots$ & $7 \cdot 5$ & & 100 & 152 & 45 & 960 & 51 \\
\hline 820 & 256 & 16 & 2 & 1 & $0 \cdot 5$ & $7 \cdot 69$ & $\begin{array}{l}\text { Between } \\
\text { OXA-6 \& -2 }\end{array}$ & 100 & 31 & 20 & 142 & 37 \\
\hline 898 & 256 & 4 & 0.25 & 0.25 & 0.03 & $6.8 \& 7.67$ & & 100 & 237 & 16 & 173 & 8 \\
\hline 1227 & 512 & 128 & 4 & 4 & 1 & $7 \cdot 67$ & $\begin{array}{l}\text { Between } \\
\text { OXA-6 \& -7 }\end{array}$ & 100 & 181 & 38 & 685 & 36 \\
\hline 2241 & 512 & 128 & 32 & 4 & 4 & $7 \cdot 67$ & $\begin{array}{l}\text { Between } \\
\text { OXA-6 \& -7 }\end{array}$ & 100 & 71 & 0.7 & 116 & 14 \\
\hline
\end{tabular}

$\mathrm{Cb}$, carbenicillin; Az, azlocillin; Caz, ceftazidime; Imp, imipenem; Mem, meropenem; pI, iso-electric point; PenG, penicillin G; Amp. ampicillin; Oxa, oxacillin; Cld, cephaloridine.

*Reference standard.

Table II. Resistance of derepressed isolates in relation to their uninduced levels of $\beta$-lactamase activity

\begin{tabular}{|c|c|c|c|c|c|c|c|c|}
\hline \multirow{2}{*}{ Group* } & \multirow{2}{*}{$\begin{array}{c}\text { Uninduced } \\
\beta \text {-lactamase activity } \\
\mathrm{U} / \mathrm{mg} \text { of protein } \dagger\end{array}$} & \multirow{2}{*}{$\begin{array}{l}\text { Number } \\
\text { of } \\
\text { isolates }\end{array}$} & \multirow{2}{*}{$\begin{array}{l}\text { Number } \\
\text { remaining } \\
\text { inducible§ }\end{array}$} & \multicolumn{5}{|c|}{ Geometric mean MIC $(\mathrm{mg} / \mathrm{L})$} \\
\hline & & & & Ceftazidime & Azlocillin & Carbenicillin & Imipenem & Meropenem \\
\hline 1 & $45-100$ & 7 & 7 & $8 \cdot 8$ & $86 \cdot 1$ & $128 \cdot 0$ & $1 \cdot 8$ & 10 \\
\hline 2 & $101-300$ & 7 & 7 & $13 \cdot 1$ & $156 \cdot 0$ & $141 \cdot 3$ & 1.0 & 0.7 \\
\hline 3 & $301-1000$ & 23 & 22 & $18 \cdot 6$ & $128 \cdot 0$ & $120 \cdot 5$ & 1.5 & 0.7 \\
\hline 4 & $1001-3000$ & 11 & 4 & $26 \cdot 5$ & $225 \cdot 7$ & 186.8 & 1.5 & 1.2 \\
\hline 5 & $3001-10000$ & 3 & 0 & $50 \cdot 8$ & $256 \cdot 0$ & 161.2 & $1 \cdot 3$ & 0.8 \\
\hline 6 & $10001-300000$ & 3 & 0 & $101 \cdot 0$ & $406 \cdot 3$ & $406 \cdot 3$ & $5 \cdot 0$ & $2 \cdot 0$ \\
\hline \multicolumn{9}{|l|}{ Controls } \\
\hline R20 & 8.0 & 1 & 1 & 2 & 4 & 64 & 2 & 0.25 \\
\hline Survey & ND & 1924 & ND & $2 \cdot 3$ & $8 \cdot 1$ & $66 \cdot 5$ & $1 \cdot 1$ & $0 \cdot 4$ \\
\hline
\end{tabular}

${ }^{*}$ Graded by level of uninduced $\beta$-lactamase activity.

$\dagger 1$ Unit: 1 nmole nitrocefin hydrolysed $/ \mathrm{min}$ at $37^{\circ} \mathrm{C}$ and $\mathrm{pH} 7 \cdot 0$.

$\ddagger$ Data for all 1991 isolates collected in the survey, except those with stable derepression or secondary $\beta$-lactamases.

§Inducibility was assessed with cefoxitin $500 \mathrm{mg} / \mathrm{L}$ as inducer and isolates giving less than two-fold induction were counted as uninducible.

inhibitor-free test only after c. 5-10 min. These reactions were inhibited completely by cloxacillin, but not by clavulanate, and were taken to reflect the chromosomal AmpC $\beta$-lactamase, which is universally present in $P$. aeruginosa and which normally, without induction, is expressed weakly. ${ }^{3}$ The remaining 70 resistant isolates gave faster nitrocefin reactions than strain R20; many gave an immediate red colour and all did so within 2-3 min. For 57 isolates, and the derepressed control strains 1405-con and 2297-con, these reactions were inhibited by cloxacillin but not by clavulanate; for the other 13 isolates, the reactions were inhibited by clavulanate but not cloxacillin.

\section{Isolates giving strong nitrocefin reactions, inhibited by clavulanate but not cloxacillin}

This pattern indicated production of secondary $\beta$ - lactamase(s), as the AmpC type has the converse inhibition profile. ${ }^{3,17}$ Electrofocusing and hydrolysis assays were used to test this inference, and to characterise the $\beta$-lactamases (table I). PSE- 1 enzyme was found in five isolates and PSE-4 in one (table I). The other seven isolates had OXA enzymes, as characterised by stronger activity against oxacillin than benzylpenicillin or carbenicillin. Three OXAproducers (isolates 520, 543 and 556) were probably replicates; they were from the same hospital and had the same enzyme. This $\beta$-lactamase co-focused with OXA-4, but was relatively more active against ampicillin and less so against oxacillin. The remaining four isolates had unique OXA-type enzymes, none of which co-focused with any previously described type. Electrofocusing revealed two $\beta$-lactamase activities (pI 6.8 and 7.67) in one of these isolates (898), and it remains uncertain whether these were satellite bands 
of a single enzyme or were distinct. Further studies on all these OXA enzymes are in progress.

Isolates with PSE-1 and PSE-4 enzymes were highly resistant to carbenicillin and azlocillin but remained susceptible to both carbapenems and, with one exception (isolate 2312), to ceftazidime (table I). Isolates with OXA enzymes were less resistant to penicillins than those with PSE types. One OXA-producer (2241), was resistant to ceftazidime but the others were susceptible to this cephalosporin (table I).

\section{Isolates giving strong nitrocefin reactions, inhibited by cloxacillin but not clavulanate}

This pattern - also observed for the derepressed controls 1405-con and 2297-con-indicated hyperproduction of the AmpC chromosomal $\beta$-lactamase, but it might arise via production of another enzyme with similar inhibitor susceptibility. It could also occur trivially, for normal isolates, if nitrocefin tests were over-inoculated. Electrofocusing and specific activity determinations were undertaken to distinguish these possibilities. All 57 isolates had $\beta$-lactamases with isoelectric points $>7 \cdot 5$; only the AmpC enzymes have such high iso-electric points and are inhibited by cloxacillin but not clavulanate. Quantitative nitrocefin assays confirmed that 54 of the 57 isolates produced at least five-fold higher uninduced levels of $\beta$-lactamase than strain R20, confirming derepression (table II). The remaining three isolates had uninduced enzyme levels scarcely above that of strain R20 and were transferred to the group of organisms (below) in which resistance was considered to be $\beta$-lactamase-independent. In 40 of the 54 isolates, $\beta$-lactamase expression remained inducible by cefoxitin, indicating that derepression was only partial. The remaining 14 isolates had the highest $\beta$-lactamase specific activities, 90-2900-fold greater than that of strain R20, and were totally derepressed (table II). Resistance to azlocillin was almost universal amongst the derepressed isolates, with 53 of 54 of them resistant to this penicillin at $16 \mathrm{mg} / \mathrm{L}$ and 50 resistant at $32 \mathrm{mg} / \mathrm{L}$. Insusceptibility to ceftazidime was also frequent, with 51 isolates resistant at $4 \mathrm{mg} / \mathrm{L}$ and 25 isolates resistant to $16 \mathrm{mg} / \mathrm{L}$. Some derepressed isolates were more widely resistant, 25 were insensitive to carbenicillin $128 \mathrm{mg} / \mathrm{L}$, seven insensitive to imipenem $4 \mathrm{mg} / \mathrm{L}$ and two insensitive to meropenem $4 \mathrm{mg} / \mathrm{L}$. Generally, however, the level of resistance to carbenicillin and the carbapenems was unrelated to the amount of $\beta$-lactamase produced without induction, whereas resistance to azlocillin and ceftazidime was strongly related to enzyme activity (table II).

\section{Penicillin- or ceftazidime-resistant isolates that did not give strong nitrocefin reactions}

The 274 isolates initially placed in this category were supplemented with the three initially mis-classified as giving strong, cloxacillin-inhibited, nitrocefin reactions (see above). Of the total of 277 isolates, 195 were resistant to carbenicillin at $128 \mathrm{mg} / \mathrm{L}$ and had reduced susceptibility, compared to modal MICs, to azlocillin, ceftazidime, meropenem and ciprofloxacin, although not to imipenem (fig. 1). This is the typical pattern of "intrinsic resistance" and isolates with this mechanism constituted the upper "tail" of a continuous distribution, not a discrete cluster. This last point is illustrated in fig. 2 , which shows that the MICs of azlocillin, ceftazidime, meropenem and, to some extent, ciprofloxacin were related to those of carbenicillin across the whole spectrum of carbenicillin susceptibility and resistance represented in the survey collection, not just for the 195 isolates in the present group. The remaining 82 isolates in the present group were resistant to one or both of ceftazidime $4 \mathrm{mg} / \mathrm{L}$ or azlocillin $16 \mathrm{mg} / \mathrm{L}$ and, like isolates with the classical form of intrinsic resistance, had reduced susceptibility to meropenem. They nevertheless remained fully susceptible to carbenicillin and ciprofloxacin, as well as to imipenem (fig. 1).

\section{Isolates resistant to carbapenems}

Resistance to carbapenems was considered separately, since imipenem resistance in $P$. aeruginosa is largely independent of that to penicillins and cephalosporins. ${ }^{\mathbf{1}, \mathbf{2 , 9}}$ Of the 1991 isolates collected in the survey, 59 were resistant to one or both carbapenems at $4 \mathrm{mg} / \mathrm{L}$. Of these, 39 were resistant to imipenem alone, 10 to meropenem alone and 10 to both compounds. Thus, cross-resistance between the two carbapenems was very incomplete. Most (27 of 39) of the isolates resistant to imipenem but not meropenem had modal susceptibility to other $\beta$ lactam agents, except meropenem, to which MICs were raised to $2-4 \mathrm{mg} / \mathrm{L}$, as compared to a modal value of $0.5 \mathrm{mg} / \mathrm{L}$. None of these 27 isolates gave a strong nitrocefin reaction. The other 12 isolates in the group had intrinsic resistance $(\mathrm{n}=7)$ or $\beta$-lactamase derepression $(n=5)$ and, consequently, had broader resistances. Of the 20 isolates resistant to meropenem alone or to both carbapenems, 17 had intrinsic resistance to penicillins and cephalosporins, two had stable derepression and one was fully susceptible to every other $\beta$-lactam agent. Thus, meropenem resistance, although rarer than imipenem resistance, was much more strongly associated with intrinsic resistance to other $\beta$-lactam agents (17 of 20 cf. 7 of 39 ; $\mathrm{p}<0.01, \chi^{2}$ test).

Attempts to determine whether carbapenem-resistant isolates lacked D2 porin, which provides outermembrane pores permeable to carbapenems but not other $\beta$-lactam agents, were unsuccessful (not shown), because comparisons to isogenic carbapenem-susceptible parents were not available.

\section{Sources of isolates with various modes of resistance}

Table III summarises the distribution of resistance 

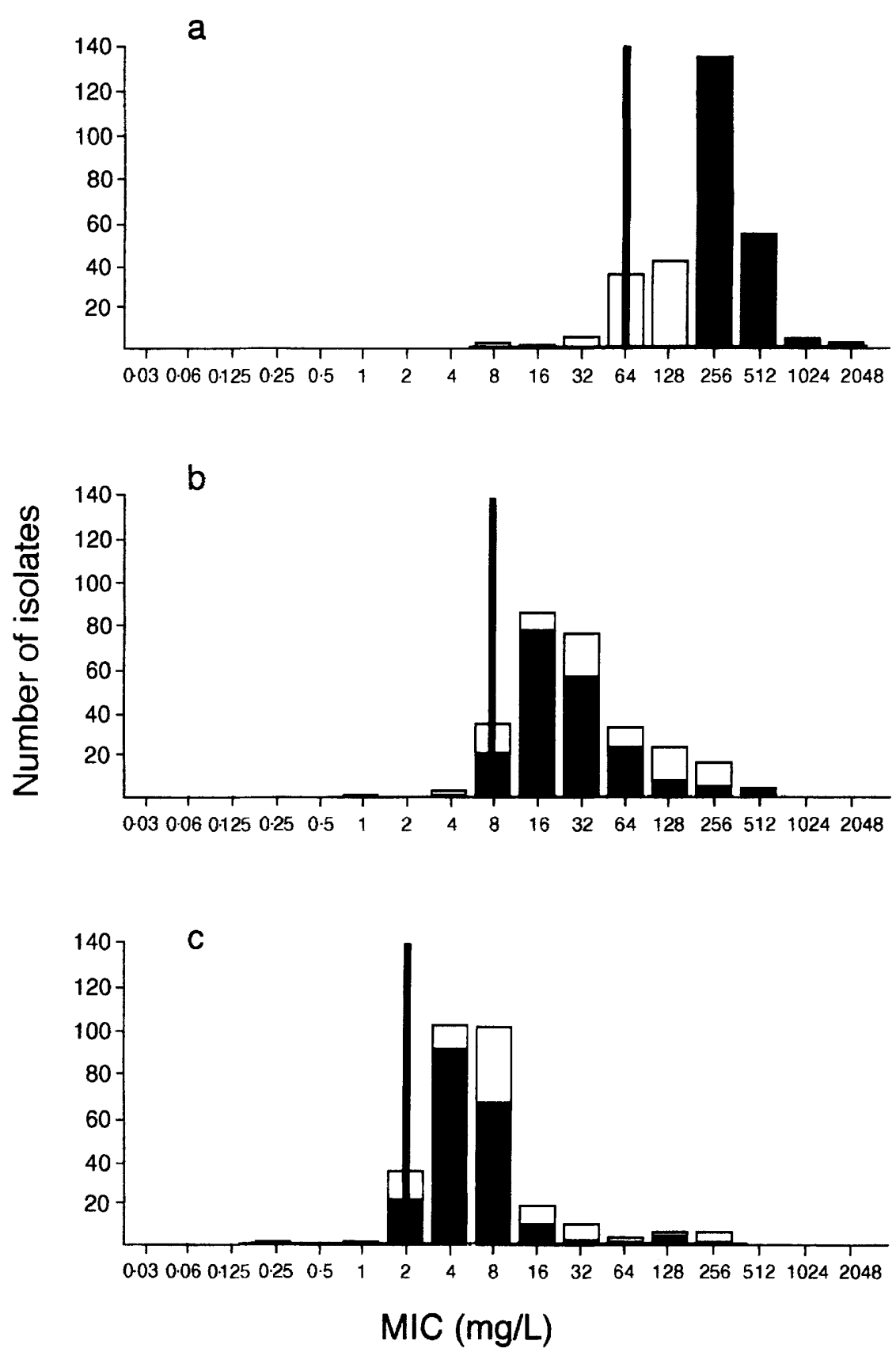

Fig. 1. For legend see p. 305

mechanisms in relation to patient type. Chromosomal $\beta$-lactamase derepression and intrinsic resistance were significantly more frequent amongst isolates from general in-patients than in those from out-patients, whereas imipenem resistance and secondary $\beta$ lactamases were randomly distributed amongst isolates from these groups of patients. Every resistance mechanism appeared commoner in isolates from intensive care unit patients than in those from general inpatients but statistical significance at $p<0.05$ was achieved only with respect to imipenem resistance.

\section{Discussion}

Three hundred and seventy-two $P$. aeruginosa isolates resistant to one or more of azlocillin $16 \mathrm{mg} / \mathrm{L}$, carbenicillin $128 \mathrm{mg} / \mathrm{L}$, ceftazidime $8 \mathrm{mg} / \mathrm{L}$, imipenem $4 \mathrm{mg} / \mathrm{L}$ and meropenem $4 \mathrm{mg} / \mathrm{L}$ were examined. These concentrations served to divide isolates in which a specific resistance mechanism seemed likely from those with normal susceptibility. ${ }^{11}$ MICs two-fold above these values may still denote clinical susceptibility, except for carbenicillin. For ceftazidime, a clinical breakpoint of $16 \mathrm{mg} / \mathrm{L}$ (fourfold above the present value) is defensible. The mechanism(s) present in the resistant isolates were investigated and the frequencies of individual mechanisms were compared to those found in a similar survey in 1982. ${ }^{12.13}$ Methods of speciation and susceptibility testing were identical in both surveys, but there were differences in collection strategy. Although 24 hospitals participated in each survey, only 18 participated in both; moreover, the number of isolates from each hospital varied more widely in 1982, from two to 330, compared with 17-98 in 1993. 

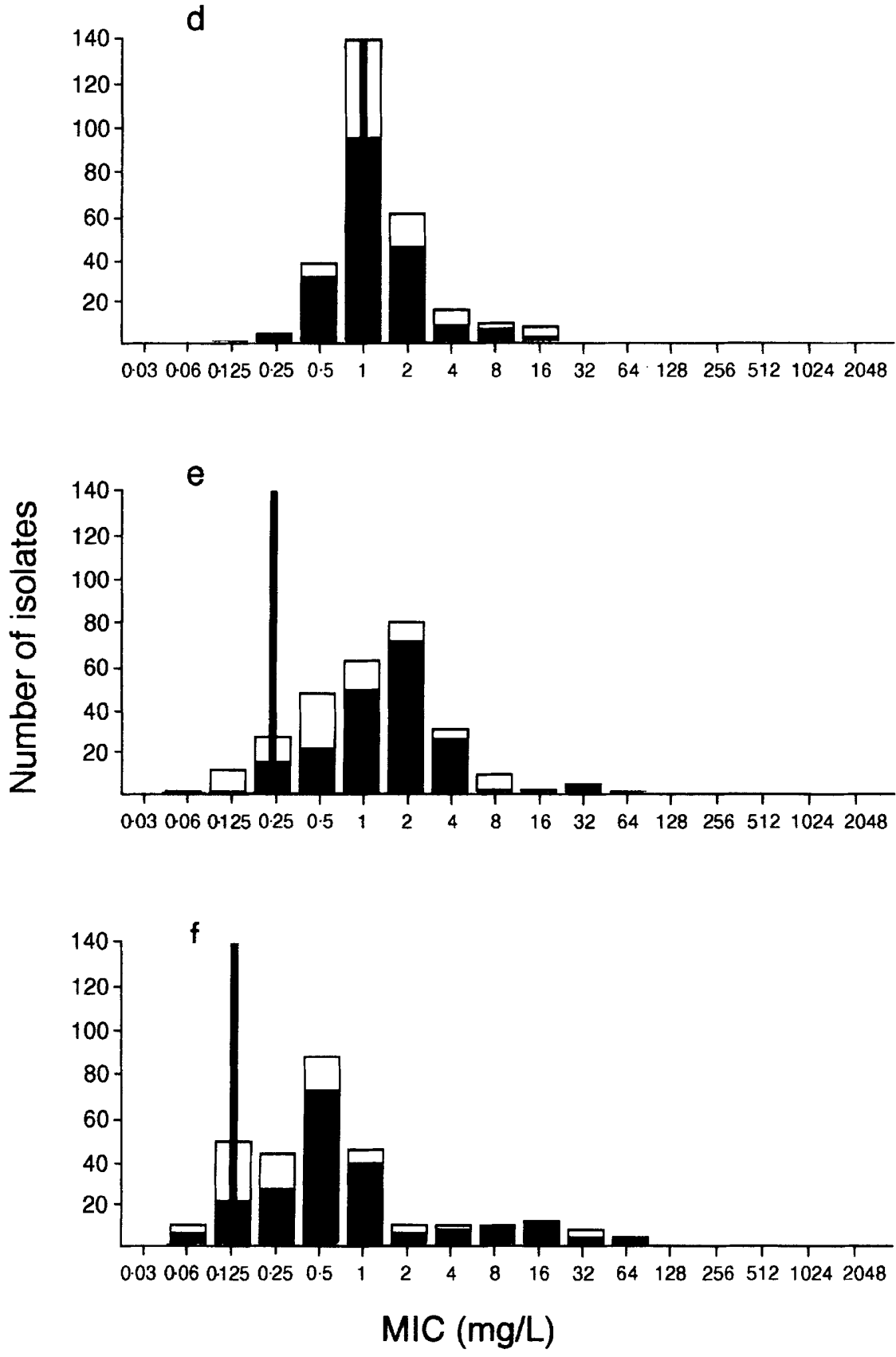

Fig. 1. MICs of antimicrobial agents for isolates with intrinsic resistance. $\square$, Data for 195 isolates resistant to carbenicillin $128 \mathrm{mg} / \mathrm{L}$; $\square$, data for 82 carbenicillin-susceptible isolates included because of their resistance to azlocillin $16 \mathrm{mg} / \mathrm{L}$ or ceftazidime $4 \mathrm{mg} / \mathrm{L}$, or both. Panel a, carbenicillin; b, azlocillin; $\mathbf{c}$, ceftazidime; $\mathbf{d}$, imipenem; $\mathbf{e}$, meropenem; $\mathbf{f}$, ciprofloxacin. The vertical bars indicate the modal MICs for the collection of 1991 isolates.

$\beta$-Lactamase-mediated resistance remained rare. Secondary $\beta$-lactamases were found in only 13 of the 1991 present isolates and in 47 of 1866 collected in 1982. Comparison of these proportions indicates a significant decrease $\left(p<0.01, \chi^{2}\right.$ test $)$ but few producers were obtained in either year, and analysis was prone to distortion by outbreak strains. In 1982, one hospital contributed 10 indistinguishable isolates with PSE-4 enzyme; another sent 10 with an OXAtype, possibly OXA-6, and three further hospitals sent pairs of likely replicates. In the present study, one hospital sent three isolates (520, 543 and 556: table I) with the same novel OXA enzyme. In this situation it is better to compare the proportions of hospitals sending isolates with secondary $\beta$-lactamases; this declined insignificantly, from 14 of 24 in 1982 to 8 of 24 in $1993\left(\mathrm{p}>0.05, \chi^{2}\right.$ test). The scarcity of secondary $\beta$-lactamases in $P$. aeruginosa from the UK is apparent from other studies. ${ }^{18,19}$ Such enzymes are commoner among $P$. aeruginosa isolates from France $^{20}$ and Catalonia, ${ }^{21}$ occurring in $7-12 \%$ of isolates, but remain much rarer than in enterobacteria, where they are produced by $30-50 \%$ of isolates. ${ }^{22}$ Moreover, the predominant enzymes differ amongst bacterial families: PSE-1 and PSE-4 types are commonest in $P$. aeruginosa ${ }^{13,20,21,23}$ as confirmed here, whereas the TEM and SHV types predominate in enterobacteria. ${ }^{22}$ A scatter of OXA enzymes was found here (table I), as in previous surveys of $P$. aeruginosa ${ }^{13,21,23}$ but no individual member of this enzyme class is frequent in 


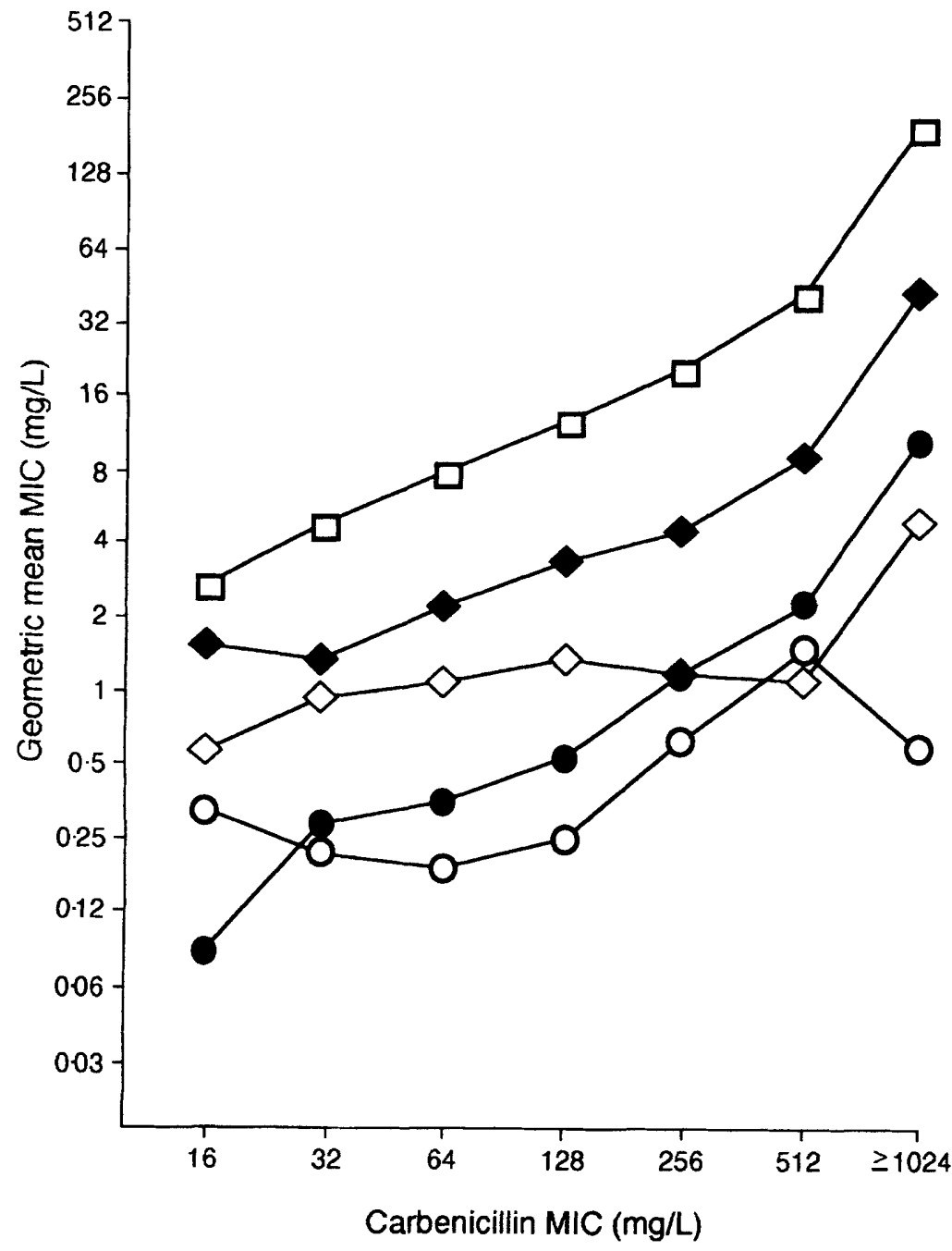

Fig. 2. Inter-relationship of MICs of different antimicrobial agents with those of carbenicillin for all $P$. aeruginosa isolates collected in the survey, except those with stable derepression or secondary $\beta$-lactamases $(\mathrm{n}=1924)$. The 195 isolates with classical intrinsic carbenicillin resistance fall to the right-hand side of the graph (MIC $\geqslant 256 \mathrm{mg} / \mathrm{L}$ ). Lines are: azlocillin $\square$, ceftazidime $\bullet$, ciprofloxacin $\bigcirc$, imipenem $\diamond$, meropenem

Table III. Distribution of resistance mechanisms amongst $P$. aeruginosa isolates from various types of patients

\begin{tabular}{|c|c|c|c|c|c|}
\hline $\begin{array}{l}\text { Mechanisms } \\
\text { (number of isolates) }\end{array}$ & $\begin{array}{l}\text { ICU } \\
(134)\end{array}$ & $\longleftarrow \mathrm{p}^{\dagger} \longrightarrow$ & $\begin{array}{l}\text { Other in-patient } \\
\text { (1041) }\end{array}$ & $-\mathrm{p}_{\dagger} \longrightarrow$ & $\begin{array}{l}\text { Out-patient } \\
\text { (797) }\end{array}$ \\
\hline Secondary $\beta$-lactamase (13) & 4 & 0.056 & 7 & 0.62 & 2 \\
\hline Stably derepressed (54) & 10 & 0.052 & 34 & 0.0104 & 10 \\
\hline Intrinsically resistant $\left(273^{*}\right)$ & 27 & 0.34 & 162 & 0.0036 & 84 \\
\hline All imipenem-resistant (49) & 13 & $<0.0001$ & 19 & 1.0 & 17 \\
\hline $\begin{array}{l}\text { Imipenem-resistant and } \\
\text { intrinsically resistant (15) }\end{array}$ & 4 & 0.056 & 7 & $1 \cdot 0$ & 4 \\
\hline $\begin{array}{l}\text { Imipenem-resistant and stably } \\
\text { derepressed (7) }\end{array}$ & 2 & 0.28 & 4 & $0 \cdot 8$ & 1 \\
\hline
\end{tabular}

*Does not total 277 , as elsewhere, since sources of four intrinsically resistant isolates were unrecorded.

tIsolates from non-ICU in-patients were taken as a reference group to which isolates from other patient groups were compared by Fisher's exact tests, with the $p$ values thereby obtained being adjusted by the Bonferroni correction (i.e., doubled in the present cases) to compensate for the fact that two comparisons (one for ICU isolates and one for out-patient isolates) were being made to a single reference group (the in-patient isolates). The groups being compared are indicated by the arrows.

the species. A difference from the 1982 survey was that PSE-1 replaced PSE-4 as the commonest enzyme. Notably, all the 19 PSE-4 producers collected in 1982 were of serogroup O:II and, although from 10 hospitals, most gave similar phage lysis patterns. ${ }^{24}$ These findings suggested clonal spread of a resistant strain, which has since disappeared.
Isolates with secondary $\beta$-lactamases mostly were resistant to the penicillins but susceptible to ceftazidime and the carbapenems, reflecting the known activity of PSE and OXA enzymes. ${ }^{17}$ One isolate with a novel OXA enzyme (2241) was resistant to ceftazidime (MIC $32 \mathrm{mg} / \mathrm{L}$ ) but it is doubtful whether the resistance involved the $\beta$-lactamase which, when 


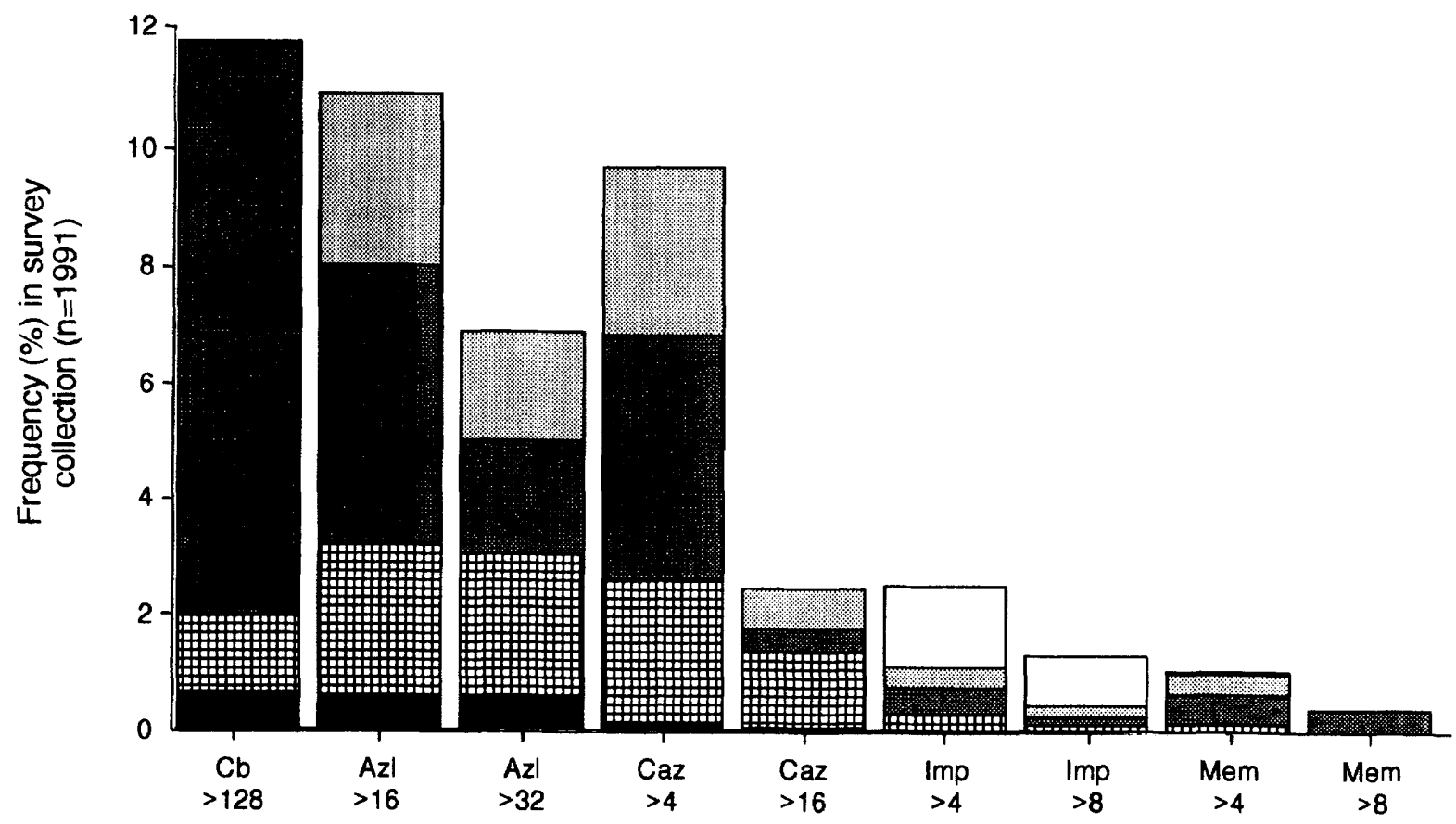

Resistance taken as MIC (mg/L)

Fig. 3. Distribution of resistance mechanisms amongst isolates resistant to the antimicrobial concentrations $(\mathrm{mg} / \mathrm{L})$ indicated on the horizontal axis: secondary $\beta$-lactamase production $\mathbf{\square}$; stable derepression of chromosomal $\beta$-lactamase $\boxplus$; intrinsic resistance affecting all penicillins and cephalosporins 娄; intrinsic resistance affecting only azlocillin and ceftazidime 0 ; imipenem-specific resistance probably caused by loss of D2 porin $\square$; meropenem-specific resistance $\mathbb{Q}$. Abbreviations are: $\mathrm{Cb}$, carbenicillin; Az, azlocillin; Caz, ceftazidime; Imp, imipenem and Mem, meropenem. Data are analysed with regard to the low breakpoints used elsewhere in this study, and with respect to high breakpoints which may be considered as the limits of clinical susceptibility. ${ }^{11}$ It is emphasised that detection of a mechanism does not prove it to be the sole cause of resistance: e.g., although $\beta$-lactamase derepression and intrinsic resistance were present in some imipenem-resistant isolates they do not cause this resistance $;^{1.2}$ likewise stable derepression does not cause meropenem resistance ${ }^{2}$ and it is doubtful whether the OXA $\beta$-lactamase found in one ceftazidime-resistant isolate (2241, see table I) was responsible for that resistance.

extracted, had only feeble activity against $0.5 \mathrm{~mm}$ ceftazidime (not shown).

The survey yielded 54 stably derepressed isolates, defined as those with at least five-fold higher uninduced AmpC $\beta$-lactamase activity than strain R20. Nineteen isolates were classed as derepressed in the 1982 survey, only 17 of which would meet the present definition. ${ }^{13}$ This increase (17 of 1866 cf. 54 of 1991) was significant $\left(p<0.01 ; \chi^{2}\right.$ test). Moreover, the change was not a consequence of multiple inclusion of outbreak strains; the isolates from the 1982 survey came from only 8 of 24 participating hospitals and included one pair of likely replicates, whereas those from the present survey were from 19 of 24 hospitals and included three pairs of likely replicates and one set of four. The proportion of hospitals sending derepressed isolates had increased compared to 1982 $\left(p<0.01, \chi^{2}\right.$ test). These increases are not surprising. Ureidopenicillins and extended-spectrum cephalosporins, used increasingly since the early 1980 s, are labile to AmpC enzymes but are weak inducers of their synthesis, and so select derepressed mutants from inducible populations. ${ }^{1-3}$ Carboxypenicillins, which were the main antipseudomonal $\beta$-lactams before 1980 , are more stable and less selective. ${ }^{1}$ Although derepressed organisms remain rare it is telling that most were from in-patients and, especially, those in intensive care units (table III). These are the patients in whom antibiotic selection pressure is greatest. The degree of resistance of derepressed organisms to azlocillin and ceftazidime reflected the amount of enzyme produced without induction (table II) whereas resistance to the more stable agents, carbenicillin, imipenem and meropenem, was not related to enzyme quantity.

The largest group of $\beta$-lactam-resistant isolates were those lacking untoward $\beta$-lactamase activity and with inter-related resistance to penicillins, ceftazidime, ciprofloxacin and meropenem, although not to imipenem (fig. 1). This antibiogram profile is wellknown in $P$. aeruginosa, and has been termed "intrinsic resistance", ${ }^{2,5,6}$ Its mechanism was long assumed to be impermeability, because other mechanisms were contra-indicated and because it was difficult to envisage anything else that could compromise such diverse drugs. ${ }^{5}$ However, recent biophysical data suggest increased multi-drug efflux as the mechanism, ${ }^{7,8}$ and a multi-drug efflux operon, cloned from the species, was shown to enhance resistance to quinolones, tetracycline and chloramphenicol. ${ }^{25}$ Nevertheless, it remains surprising that such a system should affect $\beta$-lactam agents, which have targets external to the cytoplasmic membrane. In the present survey, 195 of 1991 isolates were inferred to have classical intrinsic resistance, with carbenicillin MICs $>128 \mathrm{mg} / \mathrm{L}$ and with reduced susceptibility to ceftazidime, azlocillin, meropenem and ciprofloxacin. 
This proportion compares to 131 of 1866 in 1982 and represents a significant increase $\left(\mathrm{p}<0.01 ; \chi^{2}\right.$ test). Eighty-two further carbenicillin-susceptible (MIC $\leqslant$ $128 \mathrm{mg} / \mathrm{L}$ ) isolates were resistant to either or both of azlocillin and ceftazidime and, mostly, had reduced susceptibility to meropenem (fig. 1). No similar group was recognised in 1982 and their mechanism of resistance, although uncertain, seems most likely to entail some combination of impermeability or efflux.

The final mechanisms considered were those affecting carbapenems. Imipenem resistance in $P$. aeruginosa commonly emerges via mutational loss of D2 outer-membrane protein. ${ }^{9,10}$ This does not affect non-carbapenems, which cannot traverse the narrow pores formed by this specialised porin, ${ }^{10}$ and generally does not raise meropenem MICs above $2-4 \mathrm{mg} / \mathrm{L}$. Most or all the 49 isolates resistant to imipenem $4 \mathrm{mg} / \mathrm{L}$ seem likely to have lacked this porin, but this could not be confirmed in the absence of isogenic porin-producing controls (not shown). Although a few imipenem-resistant isolates had derepression of AmpC enzymes or intrinsic resistance, neither of these mechanisms generally affects imipenem. ${ }^{2}$ Resistance to meropenem $4 \mathrm{mg} / \mathrm{L}$ only partly overlapped that to imipenem, being seen in 10 of 49 imipenem-resistant isolates and in a further 10 imipenem-susceptible organisms. In 17 of these 20 organisms, the meropenem resistance was associated with intrinsictype resistance to other $\beta$-lactam agents. Both the present (figs. 1 and 2 ) and previous studies ${ }^{2,6}$ support the view that the intrinsic resistance mechanism affects meropenem, although frank resistance is rarely conferred.

The distribution of mechanisms amongst isolates resistant at either the low microbiological breakpoints used throughout this Discussion or at higher breakpoints, thought to represent the limits of clinical susceptibility, ${ }^{11}$ is summarised in fig. 3 . It is emphasised that the occurrence of a mechanism does not prove it to be the sole cause of resistance, and cases where the mechanisms found do not account for observed resistance are indicated in the legend. It is possible also that some isolates may have possessed further, undetected mechanisms, such as nitrocefin-negative $\beta$ lactamases. More generally, the MICs of $\beta$-lactam agents reflect the balance of penicillin-binding protein sensitivity, $\beta$-lactamase activity, permeability and efflux and ascribed "resistance mechanisms" are merely those factors whose change shifts the MIC beyond the normal range. Finally, it should be stressed that even "susceptible" $P$. aeruginosa strains have considerable defences against $\beta$-lactam agents, being 100 -fold less susceptible than those mutants which lack both $\beta$-lactamase inducibility and multi-drug efflux and which are hyperpermeable. ${ }^{7,8,26}$

We are grateful to the following individuals and their colleagues for their participation in the study: Dr A.W. Anderson, York District Hospital; Dr P. Cockcroft, St Mary's Hospital, Portsmouth; Professor B. I. Duerden, University Hospital of Wales, Cardiff; Dr F.X. S. Emmanuel, City Hospital, Edinburgh; Dr I. Gould, Aberdeen Royal Infirmary; Drs J. Hood and G. F. S. Edwards, Glasgow Royal Infirmary; Dr A. J. Howard, Ysbyty Gwynedd, Bangor (Wales); Mr M. R. Howard, Manchester Royal Infirmary; Mr R. P. Human, Derriford Hospital, Plymouth; Dr H. R. Ingham, Newcastle General Hospital; Dr M. Keaney, Salford Royal Hospitals NHS Trust (Hope Hospital), Salford; Dr P. G. Murphy, Belfast City Hospital; Professor A. Percival, Royal Liverpool University Hospital; Dr G. L. Ridgeway, University College Hospital, London; Dr M. H. Robertson, Herts and Essex Hospital, Bishop's Stortford; Dr N. Saunders, Hammersmith Hospital, London; Dr E. T. M. Smyth, Royal Victoria Hospital, Belfast; Professor D.C. E. Speller and Dr R. Jones, Bristol Royal Infirmary; Dr D. J. Waghorn, Wycombe General Hospital, High Wycombe; Dr A. B. White, Raigmore Hospital, Inverness; Dr W. D. White, Barking Hospital; Dr P.J. Wilkinson, University Hospital, Nottingham; Professor J. D. Williams, Royal London Hospital; Dr R. Wise, Dudley Road Hospital, Birmingham. We are grateful to Zeneca Pharmaceuticals (UK) for financial support and to Mr G. Byttebier of Zeneca Pharmaceuticals NV Benelux, for his advice and help on statistical analyses.

7. Li X-Z, Livermore DM, Nikaido H. Role of efflux pump(s) in intrinsic resistance of Pseudomonas aeruginosa: resistance to tetracycline, chloramphenicol, and norfloxacin. Antimicrob Agents Chemother 1994; 38: 1732-1741.

8. Li X-Z, Ma D, Livermore DM. Nikaido H. Role of efflux pump(s) in intrinsic resistance of Pseudomonas aeruginosa: resistance to tetracycline, chloramphenicol, and norfloxacin. Antimicrob Agents Chemother 1994; 38: 1732-1741.

9. Büscher KH, Cullmann W, Dick W, Opferkuch W. Imipenem resistance in Pseudomonas aeruginosa resulting from diminished expression of an outer membrane protein. Antimicrob Agents Chemother 1986; 31: 703-708.

10. Trias J, Nikaido $\mathbf{H}$. Outer membrane protein D2 catalyzes the facilitated diffusion of carbapenems and penems through the outer membrane of Pseudomonas aeruginosa. Antimicrob Agents Chemother 1990; 34: 52-57.

11. Chen HY, Yuan M, Ibrahim-Elmagboul IB, Livermore DM Susceptibility and resistance to antimicrobials amongst Pseudomonas aeruginosa isolates collected in the UK in 1993. J Antimicrob Chemother 1995; 35: 521-534.

12. Williams RJ, Lindridge MA, Said AA, Livermore DM, Williams JD. National survey of antibiotic resistance in Pseudomonas aeruginosa. $J$ Antimicrob Chemother 1984; 14: 9-16.

13. Williams RJ, Livermore DM, Lindridge MA, Said AA, 
Williams JD. Mechanisms of $\beta$-lactam resistance in British isolates of Pseudomonas aeruginosa. J Med Microbiol 1984; 17: 283-293.

14. Livermore DM, Corkill JE. Effects of $\mathrm{CO}_{2}$ and $\mathrm{pH}$ on inhibition of TEM-1 and other $\beta$-lactamases by penicillanic acid sulfones. Antimicrob Agents Chemother 1992; 36: 1870-1876.

15. Matthew M, Harris AM, Marshall MJ, Ross GW. The use of analytical isoelectric focusing for detection and identification of beta-lactamases. J Gen Microbiol 1975; 88: $169-178$

16. Lowry OH, Rosebrough NJ, Farr AL, Randall RJ. Protein measurement with the Folin phenol reagent. J Biol Chem $1951 ; 193: 265-275$.

17. Bush K. Characterization of $\beta$-lactamases. Classification of $\beta$-lactamases: groups $1,2 \mathrm{a}, 2 \mathrm{~b}$, and $2 \mathrm{~b}^{\prime}$. Classification of $\beta$-lactamases: groups $2 \mathrm{c}, 2 \mathrm{~d}, 2 \mathrm{e}, 3$, and 4 . Antimocrob Agents Chemother 1989; 33: 259-263; 264-270; 271-276.

18. King JD, Farmer T, Reading C, Sutherland R. Sensitivity to carbenicillin and ticarcillin, and the beta-lactamases of Pseudomonas aeruginosa in the UK in 1978-1979. J Clin Pathol 1980; 33: 297-301.

19. Chen HY, Bonfiglio G, Allen M et al. Multicentre survey of the comparative in-vitro activity of piperacillin/tazobactam against bacteria from hospitalized patients in the British Isles. J Antimicrob Chemother 1993; 32: 247-266.

20. Thabaut A, Philippon A, Meyran M. $\beta$-Lactamases of
Pseudomonas aeruginosa and susceptibility against $\beta$ lactam antibiotics. Chemioterapia $1985 ; 4: 36-42$.

21. Tirado M, Roy C, Segura C, Reig R, Hermida M, Foz A. Incidence of strains producing plasmid determined $\beta$-lactamases among carbenicillin resistant Pseudomonas aeruginosa. J Antimicrob Chemother 1986; 18: 453-458.

22. Liu PYF, Gur D, Hall LMC, Livermore DM. Survey of the prevalence of $\beta$-lactamases amongst $1000 \mathrm{Gram}$-negative bacilli isolated consecutively at the Royal London Hospital. J Antimicrob Chemother 1992; 30: 429-447.

23. Stobberingh EE, Houben AW, Van Boven CPA. Distribution and characterization of $\beta$-lactamase-producing strains isolated in the southern part of the Netherlands. In: Periti P, Grassi GG (eds) Current chemotherapy and immunotherapy. Proceedings of the 12th International Congress of Chemotherapy. Washington DC, American Society for Microbiology. 1982: 747-748.

24. Livermore DM, Pitt TL, Jones CS, Crees-Morris JA, Williams RJ. PSE-4 $\beta$-lactamase: a serotype-specific enzyme in Pseudomonas aeruqinosa. J Med Microbiol 1985; 19:45-53.

25. Poole K, Krebes K, McNally C, Neshat S. Multiple antibiotic resistance in Pseudomonas aeruginosa: evidence for involvement of an efflux operon. $J$ Bacteriol 1993; 175: 7363-7372.

26. Zimmermann W. Penetration of $\beta$-lactam antibiotics into their target enzymes in Pseudomonas aeruginosa: comparison of a highly sensitive mutant with its parent strain. Antimicrob Agents Chemother; 18: 94-100. 